\title{
Anti-Diabetic Potential of the Leaves of Anisomeles malabarica in Streptozotocin Induced Diabetic Rats
}

\author{
Peddanna Kotha ${ }^{a} \quad$ Kameswara Rao Badrib,c Ramya Nagalapuram ${ }^{a}$ \\ Rajasekhar Allagadda Appa Rao Chippada ${ }^{a}$
}

aDepartment of Biochemistry, Sri Venkateswara University, Tirupati, A.P, India; ${ }^{b}$ Minority Men's Health Initiative, Transdisciplinary Collaborative Center, Hampton University, Hampton, VA, USA; 'Department of Pharmacology \& Toxicology, Cardiovascular Research Institute, Morehouse School of Medicine, Atlanta, GA, USA

\section{Key Words}

Experimental diabetes mellitus - Anti-diabetic activity - Anisomeles malabarica - Insulin sensitivity and $\mathrm{HbA} 1 \mathrm{c}$

\begin{abstract}
Background/Aims: Diabetes mellitus is a pandemic metabolic disorder that is affecting a majority of populations in recent years. There is a requirement for new drugs that are safer and cheaper due to the side effects associated with the available medications. Methods: We investigated the anti-diabetic activity of leaves of Anisomeles malabarica following bioactivity guided fractionation. The different solvent (hexane, ethyl acetate, methanol and water) extracts of $A$. malabarica leaves were used in acute treatment studies to evaluate and identify the active fraction. The ethyl acetate extract was subjected to further fractionation using silica gel column chromatography and the compounds were identified by LC-SRM/MS and GC-MS. Additional chronic treatment studies were carried out using this active fraction (AMAF) for 30 days in experimental diabetic rats. Fasting blood glucose (FBG), glycosylated hemoglobin (HbA1c), plasma insulin levels and glucose tolerance were measured along with insulin resistance/ sensitivity indicators (HOMA-IR, HOMA- $\beta$ and QUICKI) to assess the beneficial effects of $A$. malabarica in the management of diabetes mellitus. Results: Among the different solvent extracts tested, ethyl acetate extract showed maximum (66\%) anti-hyperglycemic activity. The hexane and ethyl acetate (1:1) fraction that has maximum anti-diabetic activity was identified as active fraction of $A$. malabarica (AMAF). The FBG, $\mathrm{HbA1c}$, plasma insulin levels and insulin sensitivity/resistance indicators such as glucose tolerance, HOMA-IR, HOMA- $\beta$ and QUICKI were significantly improved to near normal in diabetic rats treated with AMAF. Further, we identified key flavonoids and fatty acids as the anti-diabetic active principles from the AMAF of A. malabarica leaves. Conclusion: The results of our study suggest that Anisomeles malabarica has potential anti-diabetic activity in STZ induced diabetic rats.




\section{Introduction}

Diabetes mellitus is a metabolic disorder characterized by hyperglycemia due to altered insulin secretion from $\beta$-cells of pancreas and/or altered hepatic and peripheral tissues' insulin sensitivity [1]. The prolonged chronic hyperglycemia leads to development of dyslipidemia followed by micro and macro vascular complications [2]. According to current international diabetes federation projections, an estimated 78 million people have diabetes in the South-East Asia and this number will likely to be doubled by 2040 [3, 4]. Management of diabetes starting with oral hypoglycemic agents and insulin, is not satisfactory and also have been reported to have several side effects that include hypoglycemia, hypersensitivity, gastrointestinal discomfort, nausea, liver and heart failure, and diarrhea [5]. Right now, there is every necessity to identify novel anti-diabetic therapeutics with lesser or no side effects. Due to their lower cost, increased tolerability and fewer side effects compared to conventional anti-hyperglycemic or anti-diabetic drugs, plant based drugs are receiving increased attention towards disease control/management $[6,7]$. Plant parts and other natural components are considerable sources of medicine as evidenced by the discovery of metformin from Galega officinalis. To identify novel treatments and management strategies one should focus on conducting systematic scientific studies to identify and characterize the active principles and their efficacy in the management of diabetes mellitus.

Anisomeles malabarica is an aromatic, perennial herb belonging to the family Lamiaceae and is widely distributed throughout the southern and tropical regions of Asia [8]. The leaves of A.malabarica are used as traditional medicine in the treatment of gastrointestinal diseases, diabetes and hyperlipidemia [9]. The leaves are used in treatment of dyspepsia, catarrhal afflictions, intermittent fever, bowel disorder, boils, and tetanus from ancient period [10]. Recently another species of Anisomeles genus, Anisomeles indica, has been demonstrated to have anti-diabetic activity in streptozotocin (STZ) induced diabetic mice [11], but there are no scientific reports on the anti-diabetic activity of $A$. malabarica. Hence in the present study, systematic studies were conducted to evaluate the anti-diabetic activity of leaves of A. malabarica in STZ induced diabetic rats and also identify the active principle(s) following bioassay guided fractionation.

\section{Materials and Methods}

The flow chart of bioassay guided fractionation is outlined in Fig. 1.

\section{Collection of plant material}

Anisomeles malabarica leaves were collected from the Tirumala hills area (Andhra Pradesh) and identified by taxonomist. A voucher specimen (voucher number: 964) was deposited in the herbarium of Department of Botany, Sri Venkateswara University, Tirupati. The leaves were shade dried, mechanically ground and the obtained leaf powder was used for further studies.

\section{Induction of diabetes mellitus}

Animal studies were conducted as approved by Institute's Animal Ethics Committee of Sri Venkateswara University, Tirupati. Diabetes mellitus was induced in overnight-fasted rats by a single intraperitoneal injection of freshly prepared STZ ( $50 \mathrm{mg} / \mathrm{kg}$, dissolved in $0.1 \mathrm{M}$ cold citrate buffer, $\mathrm{pH} 4.5$ ) as described by our group earlier $[12,13]$. Diabetes was identified by polydipsia, polyuria and by measuring fasting blood glucose (FBG) levels. Rats were tested for successful induction of diabetes 3 days after STZ injection by determining FBG levels. Rats with blood glucose levels $>250 \mathrm{mg} / \mathrm{dL}$ were used for the study.

\section{Preparation of solvent extracts}

Hexane, ethyl acetate, methanol and aqueous extracts were prepared by successive solvent extraction of leaf powder in soxhlet apparatus at $65^{\circ} \mathrm{C}-70^{\circ} \mathrm{C}$. The filtrates obtained were distilled and concentrated under reduced pressure at low temperature $\left(40^{\circ} \mathrm{C}\right.$ to $\left.45^{\circ} \mathrm{C}\right)$ in Buchi rotavapor R-200 and finally freeze dried. The extracts were stored at $4^{\circ} \mathrm{C}$ in airtight containers until used for further studies. 


\section{Cellular Physiology Cell Physiol Biochem 2017;43:1689-1702 and Biochemistry \begin{tabular}{c|c|c|c|} 
DOI: 10.1159/000484030 & O 2017 The Author(s). Published by S. Karger AG, Basel \\
Published online: October 18, 2017 & www.kargercom/cpb
\end{tabular}

Fig. 1. Bioassay guided fractionation of leaves of Anisomeles malabarica. Values in the parenthesis indicate the percentage of fall in fasting blood glucose.

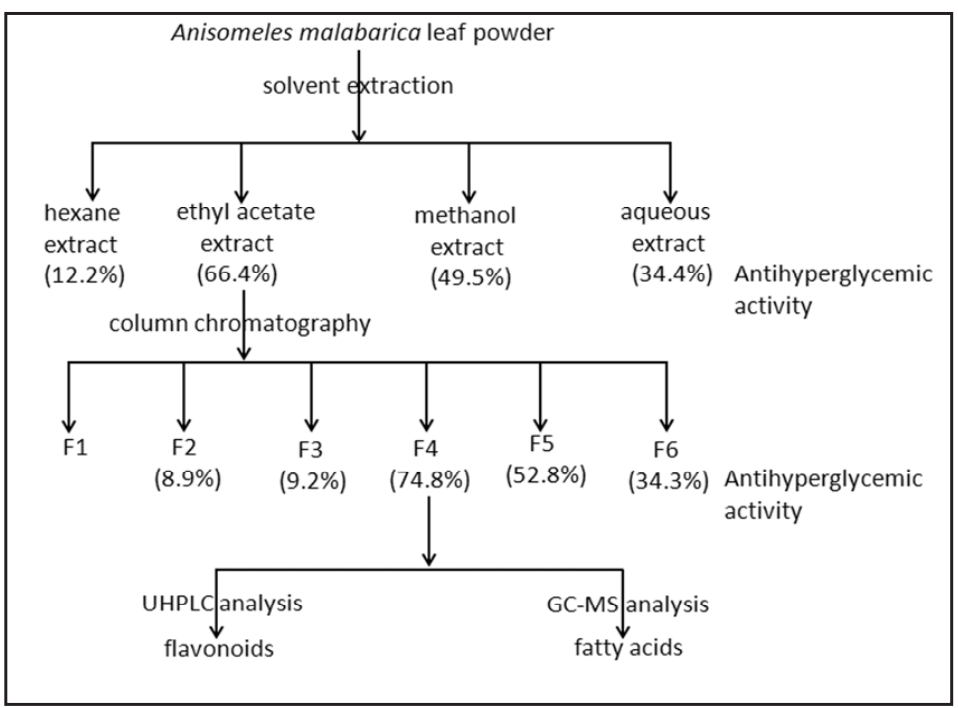

Experimental design

Effect of acute treatment with different solvent extracts of A. malabarica leaves in experimental diabetic rats:

The animals were divided into 7 groups with 6 rats in each group.

Group I: normal untreated rats

Group II: diabetic untreated rats

Group III: diabetic rats treated with hexane extract

Group IV: diabetic rats treated with ethyl acetate extract

Group V: diabetic rats treated with methanol extract

Group VI: diabetic rats treated with aqueous extract

Group VII: diabetic rats treated with glibenclamide (standard oral anti-diabetic drug)

After an overnight fast, either the extract (500 mg/kg b.w.) or the glibenclamide (20 mg/kg b.w.) suspended in water was administered to the corresponding groups of rats through oral gavage needle. Group-I and II rats were given water alone. Blood samples were collected from the tail veins of all the animals, every hour, from 0 to 6 hours after treatment for estimation of blood glucose.

\section{Isolation of active fraction using Column Chromatography}

Ten grams of ethyl acetate extract was subjected to column chromatography on silica gel (60-120 mesh size) using hexane and ethyl acetate gradient solvent system i.e. 100\% n-hexane, different ratios of $n$-hexane : ethyl acetate $(9: 1,8: 2,7: 3,6: 4,5: 5,4: 6,3: 7,2: 8$ and 1:9) and 100\% ethyl acetate. The collected fractions were analyzed by thin layer chromatography (TLC) on silica gel. The fractions with similar TLC profiles were pooled into six different fractions viz. F1 to F6. The obtained fractions were distilled and concentrated under reduced pressure at low temperature $\left(40^{\circ} \mathrm{C}\right.$ to $\left.45^{\circ} \mathrm{C}\right)$ in Buchi rotavapor $\mathrm{R}-200$, freeze dried and were stored at $4^{\circ} \mathrm{C}$ until further studies.

\section{Evaluation of anti-hyperglycemic activity of the fractions (F1-F6) in acute treatment studies}

All six fractions (F1 to F6) were subjected to test for anti-diabetic activity in STZ induced diabetic rats. The animals were classified into nine groups $(n=6)$. Group I: normal control, Group II: diabetic control, Groups III, IV, V, VI, VII and VIII: diabetic rats received F1, F2, F3, F4, F5 and F6 fractions respectively, at a dose of $50 \mathrm{mg} / \mathrm{kg}$ b.w. Group IX: glibenclamide $(20 \mathrm{mg} / \mathrm{kg}$ b.w $)$ treated diabetic rats. After an overnight fasting either the specific fraction or glibenclamide suspended in water were administered to the animals orally by a force feeding needle. Untreated control groups received water alone. Blood samples were collected from the tail veins of the animals at hourly intervals from 0 to 6 hours after the treatment for estimation of blood glucose. Based on its highest anti-hyperglycemic activity, the fraction F4 is further referred as active fraction (AMAF). 


\section{Cellular Physiology Cell Physiol Biochem 2017;43:1689-1702 \begin{tabular}{l|l|l} 
and Biochemistry Published online: October 18, 2017 & $\begin{array}{l}\text { (c) } 2017 \text { The Author(s). Published by S. Karger AG, Basel } \\
\text { www.karger.com/cpb }\end{array}$
\end{tabular}

\section{Effect of AMAF on oral glucose tolerance (OGT)}

The oral glucose tolerance test was performed in overnight fasted rats as described earlier [12]. Five groups of diabetic rats ( $\mathrm{n}=6$ in each group) were used for this study. Glucose solution $(2 \mathrm{~g} / \mathrm{kg} \mathrm{b} . \mathrm{w})$ was administered orally to all groups of rats using a force feeding needle. Simultaneously, normal control (NC) and diabetic control (DC) rats received distilled water, normal treated rats (NT) and diabetic treated rats (DT) received $50 \mathrm{mg}$ of AMAF $/ \mathrm{kg}$ b.w. and, glibenclamide treated diabetic rats (DG) received glibenclamide $(20 \mathrm{mg} / \mathrm{kg}$ b.w.) orally. Blood samples were collected every 30 minutes from the tail veins of rats from 0 to 3 hours of glucose and AMAF/glibenclamide/placebo administration.

Effect of chronic treatment with AMAF on fasting blood glucose and plasma insulin levels of normal and diabetic rats

The animals were divided in to 5 groups of 6 rats each.

Group I (NC): normal untreated rats

Group II (NT): normal rats treated with AMAF

Group III (DC): diabetic untreated rats

Group IV (DT): AMAF treated diabetic rats

Group V (DG): glibenclamide treated diabetic rats

Active fraction (AMAF, $50 \mathrm{mg} / \mathrm{kg} \mathrm{b.w})$ and glibenclamide $(20 \mathrm{mg} / \mathrm{kg} \mathrm{b.w})$ were administered to the respective groups of rats once every day morning in fasting state for 30 days by gastric intubation. Fasting blood glucose levels were measured in all groups of animals at the beginning of the study and at the end of $8^{\text {th }}$, $15^{\text {th }}, 22^{\text {nd }}$ and $31^{\text {st }}$ days. At the end of study, after overnight fasting, animals were sacrificed by asphyxiation followed by cervical dislocation. Then blood and tissues were collected, processed and immediately stored at $80^{\circ} \mathrm{C}$ until further analysis.

\section{Biochemical analysis}

Estimation of blood glucose was carried out using dextrostix with Accucheck glucometer (Glucose oxidase method) [12, 13]. HbA1c was estimated by the method of Eross et al [14]. Plasma insulin levels were measured according to the modified method of Herbert et al. [15] using RIA kit obtained from BARC, Mumbai, India. Homeostatic model assessment of insulin resistance (HOMA-IR), $\beta$-cell function (HOMA- $\beta$ ) and quantitative insulin sensitivity check index (QUICKI) were calculated before and after treatment based on fasting glucose and insulin values of experimental rats.

The HOMA-IR and HOMA- $\beta$ were calculated using the formula [16] given below

HOMA-IR= [(fasting plasma insulin in $\mu \mathrm{U} / \mathrm{L}) \times$ fasting blood glucose in $\mathrm{mg} / \mathrm{dL}) / 405]$

HOMA- $\beta=$ [(360 $\mathrm{x}$ fasting plasma insulin in $\mu \mathrm{U} / \mathrm{L}) /$ (fasting blood glucose in $\mathrm{mg} / \mathrm{dL}-63)]$

QUICKI of experimental rats was also calculated using the formula [17]:

QUICKI $=1 /$ [log (fasting plasma insulin in $\mu \mathrm{U} / \mathrm{L}$ ) + log (fasting blood glucose in $\mathrm{mg} / \mathrm{dL}$ )]

Liquid chromatography-selected reaction monitoring/mass spectrometry (LC-SRM/MS) analysis of AMAF

$11.2 \mathrm{mg}$ of AMAF was extracted with $1 \mathrm{ml}$ of methanol and sonicated for 2-3 minutes and centrifuged at 14, $000 \mathrm{rpm}$ for 5 minutes. The supernatant was spiked with $25 \mathrm{ng}$ of Umbelliferone, an internal standard (ISTD), and then dried under vacuum. The same procedure was followed to prepare different phenolic standards (quinic acid, gallic acid, caffeic acid, chlorogenic acid, epicatechin, leutolin, catechin, epigallocatechin-3-gallate, quercetin, naringenin, epicatechin and kaempferol) in $100 \mu \mathrm{l}$ of methanol and spiked with $10 \mu \mathrm{l}$ reference standard. The dried sample and standards were reconstituted in $100 \mu \mathrm{l}$ of $50 \%$ methanol followed by water bath sonication for 5 minutes and then centrifuged at $14,000 \mathrm{rpm}$ for 5 minutes. Ten microliters of this supernatant was finally injected into Ultra Performance Liquid Chromatographic separation (UHPLC) system (Agilent 1290I Infinity UHPLC). $10 \mathrm{mM}$ ammonium acetate in water with $0.1 \%$ formic acid was used as the mobile phase- $\mathrm{A}$ while acetonitrile with $0.1 \%$ formic acid was used as mobile phase-B. The total run time was 30 minutes and column used was shim-pack XR-ODS III, $2 \mu$, C18, 150 $\mathrm{mm}$ x $2 \mathrm{~mm}$, with a flow rate of $200 \mu \mathrm{l} / \mathrm{min}$. The column oven temperature was set to $40^{\circ} \mathrm{C}$. The UHPLC was coupled with a Thermo Fisher-TSQ vantage mass spectrometer and the selected reaction monitoring (SRM) experiment was performed on the mass spectrometer operated in both positive (4000V) as well as negative $(2800 \mathrm{~V})$ ion mode with vaporizer temperature of $300^{\circ} \mathrm{C}$. The MS parameters such as sheath gas and auxiliary gas values were set to 20 and 10 arbitrary units, respectively and the scan time was 0.05 seconds. 


\section{Cellular Physiology Cell Physiol Biochem 2017;43:1689-1702

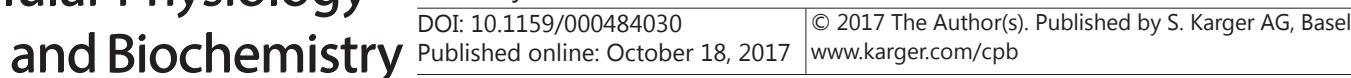 \\ Kotha et al.: Anti-Diabetic Activity of Anisomeles malabarica}

\section{GC-MS analysis of AMAF}

The AMAF was dissolved in analytical grade methanol and $2 \mu \mathrm{l}$ of the fraction was subjected to GC-MS using JEOL GCMATE II GC-MS (Agilent Technologies 6890N Network GC system for gas chromatography), equipped with secondary electron multiplier. The column (HP5) used was fused silica $50 \mathrm{~m} \times 0.25 \mathrm{~mm}$ I.D. Analysis conditions were 20 minutes at $100^{\circ} \mathrm{C}, 3$ minutes at $235^{\circ} \mathrm{C}$ for column temperature, $240^{\circ} \mathrm{C}$ for injector temperature, helium as the carrier gas and split ratio was 5:4. One micro liter sample was evaporated in a splitless injector at $300^{\circ} \mathrm{C}$ with a run time of 30 minutes. The compounds were identified by gas chromatography coupled with mass spectrometry. The molecular weight and structure of the compounds of test materials were ascertained by interpretation on mass spectrum of GC-MS using the database of National Institute Standard and Technology (NIST).

\section{Statistical analysis}

Statistical analysis was conducted using student t-test and one way ANOVA test followed by Duncan's multiple range test (DMRT).

\section{Results}

Acute effect of different solvent extracts of A. malabarica leaves in experimental diabetic rats

The effects of hexane, ethyl acetate, methanol and aqueous extracts of $A$. malabarica leaves on the fasting blood glucose levels of diabetic rats are shown in Table 1. The percentage yield of hexane, ethyl acetate, methanol and aqueous extracts of A.malabarica leaves were $9.3 \%, 22.2 \%, 10.5 \%$ and $17.1 \% \mathrm{w} / \mathrm{w}$ respectively. The ethyl acetate extract revealed maximum anti-hyperglycemic activity (66.4\% decrease in FBG after 6 hours of treatment), whereas glibenclamide has produced $33.3 \%$ reduction in the FBG levels in treated diabetic

Table 1. Effect of different solvent extracts of $A$. malabarica on fasting blood glucose levels in experimental diabetic rats. Values are given as mean \pm S.D $(n=6) .+P<0.0001$ compared with $0 \mathrm{~h}$ blood glucose levels of normal control group (group I). ${ }^{*} \mathrm{P}<0.001$ compared with the $0 \mathrm{~h}$ blood glucose levels in the respective group. ${ }^{* *} \mathrm{P}<0.0001$ compared with the $0 \mathrm{~h}$ blood glucose levels in the respective group. Numbers in parenthesis indicate the percentage of fall in blood glucose. Group I and II: Normal and diabetic untreated rats respectively; Group III, IV, V, VI and VII: Diabetic rats treated with hexane, ethyl acetate, methanol, aqueous extracts and glibenclamide respectively

\begin{tabular}{|c|c|c|c|c|c|c|c|}
\hline \multirow[b]{2}{*}{ Groups } & \multicolumn{7}{|c|}{ Fasting Blood Glucose (mg/dl) } \\
\hline & $\mathrm{Oh}$ & $1 \mathrm{~h}$ & $2 \mathrm{~h}$ & $3 \mathrm{~h}$ & $4 \mathrm{~h}$ & $5 h$ & $6 \mathrm{~h}$ \\
\hline I & $84.1 \pm 2.1$ & $86.3 \pm 2.9$ & $90.8 \pm 4.9$ & $90.8 \pm 5.3$ & $84.6 \pm 1.9$ & $89.1 \pm 4.2$ & $84.8 \pm 3.5$ \\
\hline II & $362.2 \pm 5.9 \dagger$ & $364.4 \pm 5.3$ & $367.6 \pm 6.7$ & $378.1 \pm 7.3$ & $381.9 \pm 6.3$ & $386.4 \pm 5.7$ & $392.2 \pm 6.3$ \\
\hline III & $368.4 \pm 33.9 \dagger$ & $365.2 \pm 31.3$ & $362.9 \pm 36.4$ & $459.4 \pm 49.9$ & $351.2 \pm 32.7$ & $346.9 \pm 32.7$ & $\begin{array}{c}323.8 \pm 15.7^{*} \\
(12.2 \%)\end{array}$ \\
\hline IV & $379.2 \pm 24.1 \dagger$ & $365.8 \pm 28.9$ & $350.8 \pm 54.9$ & $309.0 \pm 54.1^{* *}$ & $275.6 \pm 51.1^{* *}$ & $190.1 \pm 26.3^{* *}$ & $\begin{array}{c}127.6 \pm 19.0^{* *} \\
(66.4 \%)\end{array}$ \\
\hline $\mathrm{V}$ & $319.5 \pm 38.2 \dagger$ & $291.4 \pm 36.9$ & $290.8 \pm 36.4 *$ & $266.0 \pm 41.3$ & $239.4 \pm 46.3^{* *}$ & $203.3 \pm 52.4^{* *}$ & $\begin{array}{c}161.6 \pm 62.9^{* *} \\
(49.5 \%)\end{array}$ \\
\hline VI & $386.3 \pm 33.9 \dagger$ & $361.7 \pm 46.3$ & $341.7 \pm 46.9 *$ & $304.9 \pm 53.6$ & $293.4 \pm 53.6^{* *}$ & $281.4 \pm 50.1^{* *}$ & $\begin{array}{c}253.6 \pm 46.8^{* *} \\
(34.4 \%)\end{array}$ \\
\hline VII & $369.4 \pm 10.1 \dagger$ & $353.6 \pm 12.3$ & $327.4 \pm 13.8$ & $314.6 \pm 19.5^{*}$ & $284.3 \pm 10.7$ & $\begin{array}{c}244.8 \pm 11.8^{* *} \\
(33.8 \%)\end{array}$ & $\begin{array}{c}269.5 \pm 7.6^{* *} \\
(27.1 \%)\end{array}$ \\
\hline
\end{tabular}




\section{Cellular Physiology Cell Physiol Biochem 2017;43:1689-1702 and Biochemistry Published \begin{tabular}{l|l} 
DOI: 10.1159/000484030 & $\begin{array}{l}\text { C } 2017 \text { The Author(s). Published by S. Karger AG, Basel } \\
\text { www.karger.com/cpb }\end{array}$
\end{tabular} \\ Kotha et al.: Anti-Diabetic Activity of Anisomeles malabarica}

Table 2. Effect of acute treatment with fractions obtained by column chromatography of ethyl acetate extract of $A$. malabarica leaves in experimental diabetic rats. Values are given as mean \pm S.D $(n=6) .+P<0.0001$ compared with $0 \mathrm{~h}$ blood glucose levels of normal control group (group I). ${ }^{*} \mathrm{P}<0.001$ compared with the $0 \mathrm{~h}$ blood glucose levels in the respective group. ${ }^{* *} \mathrm{P}<0.0001$ compared with the $0 \mathrm{~h}$ blood glucose levels in the respective group. Numbers in parenthesis indicate the percentage of fall in blood glucose. Group I and II: normal and diabetic control rats respectively, Groups III to VIII: diabetic rats received F1, F2, F3, F4, F5 and F6 fractions respectively, at a dose of $50 \mathrm{mg} / \mathrm{kg}$ b.w. Group IX: glibenclamide (20 mg/kg b.w) treated diabetic rats

\begin{tabular}{|c|c|c|c|c|c|c|c|}
\hline \multirow[b]{2}{*}{ Groups } & \multicolumn{7}{|c|}{ Fasting Blood Glucose (mg/dL) } \\
\hline & $\mathrm{Oh}$ & $1 \mathrm{~h}$ & $2 \mathrm{~h}$ & $3 \mathrm{~h}$ & $4 \mathrm{~h}$ & $5 \mathrm{~h}$ & $6 \mathrm{~h}$ \\
\hline I & $82.4 \pm 37.3$ & $86.1 \pm 61.7$ & $83.4 \pm 29.5$ & $87.3 \pm 44.4$ & $85.8 \pm 19.2$ & $89.6 \pm 28.4$ & $87.2 \pm 11.3$ \\
\hline II & $392.6 \pm 25.2 \dagger$ & $390.7 \pm 32.1$ & $362.6 \pm 9.4$ & $367.8 \pm 22.3$ & $382.6 \pm 59.6$ & $391.3 \pm 38.6$ & $408.6 \pm 41.2$ \\
\hline III & $321.9 \pm 14.2 \dagger$ & $329.5 \pm 38.4$ & $340.3 \pm 54.3$ & $352.2 \pm 42.7$ & $355.4 \pm 55.2$ & $364.9 \pm 27.4$ & $373.1 \pm 50.3$ \\
\hline IV & $346.3 \pm 46.6 \dagger$ & $321.0 \pm 46.9$ & $325.5 \pm 26.1$ & $328.4 \pm 37.5$ & $322.8 \pm 29.7$ & $314.6 \pm 33.2$ & $315.9 \pm 25.9$ \\
\hline $\mathrm{V}$ & $357.8 \pm 49.1 \dagger$ & $355.5 \pm 60.0$ & $336.0 \pm 76.7$ & $331.0 \pm 81.7$ & $331.4 \pm 88.8$ & $326.8 \pm 98.5$ & $324.6 \pm 95.4$ \\
\hline VI & $413.6 \pm 12.4 \dagger$ & $294.2 \pm 41.2 *$ & $254.7 \pm 16.9 *$ & $209.3 \pm 23.9 *$ & $182.6 \pm 34.5$ & $148.1 \pm 40.4^{*}$ & $\begin{array}{c}104.2 \pm 11.6^{* *} \\
(74.8 \%)\end{array}$ \\
\hline VII & $403.5 \pm 42.1 \dagger$ & $334.1 \pm 38.7 *$ & $298 \pm 36.6$ & $267 \pm 49.8 *$ & $241.9 \pm 54.6$ & $216.0 \pm 46.8$ & $\begin{array}{c}190.1 \pm 34.6^{* *} \\
(52.8 \%)\end{array}$ \\
\hline VIII & $309.6 \pm 44.6 \dagger$ & $286.7 \pm 41.6^{*}$ & $266 \pm 29.7$ & $249 \pm 32.6$ & $234.5 \pm 32.5^{*}$ & $215.3 \pm 31.5$ & $\begin{array}{c}203.6 \pm 37.3 * \\
(34.3 \%)\end{array}$ \\
\hline IX & $377.8 \pm 33.5+$ & $357.3 \pm 26.6$ & $343 \pm 45.2$ & $298 \pm 15.3^{*}$ & $267.2 \pm 38.9$ & $244.1 \pm 61.5$ & $239.7 \pm 36.2 *$ \\
\hline
\end{tabular}

rats. Hexane, methanol and aqueous extracts showed maximum anti-hyperglycemic activity of $12.2 \%, 49.5 \%$ and $34.4 \%$ respectively in STZ diabetic rats.

Anti-hyperglycemic activity of the different fractions (F1-F6) of the ethyl acetate extract

Effect of the six fractions isolated from ethyl acetate extract of A.malabarica on FBG levels are given in Table 2. Among these fractions, fraction F4 has decreased the FBG levels significantly from $413.6 \pm 12.4 \mathrm{mg} / \mathrm{dL}$ to $104.2 \pm 11.6 \mathrm{mg} / \mathrm{dL}$ in diabetic rats after six hours of treatment. And the anti-hyperglycemic effect of fraction F4 (74.8\%) is significantly higher than that of the standard oral hypoglycemic agent glibenclamide and also those of other fractions.

Effect of AMAF on oral glucose tolerance (OGT) in normal and diabetic rats

The effects of AMAF on OGT in normal and STZ induced diabetic rats are shown in Fig. 2. The oral administration of $50 \mathrm{mg} A M A F / \mathrm{kg}$ b.w has significantly improved the glucose tolerance of the diabetic rats within 180 minutes of oral glucose load and it is similar to that of glibenclamide. While in the diabetic control rats, blood glucose levels remained elevated beyond 180 minutes of oral glucose load. No significant difference in the glucose tolerance was observed between the normal control and normal treated groups.

Effect of chronic treatment with AMAF on fasting blood glucose and plasma insulin levels of normal and diabetic rats

Effects of AMAF on FBG and plasma insulin levels are given in Table 3. During the treatment period and at the end of the treatment we observed continuous rise in the blood glucose levels in untreated diabetic rats. AMAF treated diabetic rats ( $50 \mathrm{mg} / \mathrm{kg} \mathrm{b.w.)} \mathrm{have} \mathrm{consistently} \mathrm{shown}$ significant reduction in the blood glucose levels over the period of four weeks. As anticipated, similar effects were observed in diabetic rats treated with glibenclamide. Diabetic untreated group showed significantly decreased plasma insulin levels $(6.6 \pm 0.9 \mu \mathrm{U} / \mathrm{l})$ compared to those of normal rats $(12.7 \pm 1.6 \mu \mathrm{U} / \mathrm{l})$, whereas treatment with AMAF significantly 
increased the plasma insulin levels $(9.6 \pm 0.6 \mu \mathrm{U} / \mathrm{l})$ in the diabetic treated group. Elevated plasma insulin levels were also observed in glibenclamide treated diabetic rats $(8.4 \pm 1.1$ $\mu \mathrm{U} / \mathrm{l}$ ) indicating the presence of remnant pancreatic $\beta$-cells in STZ diabetic rats. There were no significant changes in plasma insulin levels of normal treated rats after the treatment.

\section{Effect of AMAF on insulin sensitivity (HOMA-IR,} HOMA- $\beta$ and QUICKI scores) in normal and diabetic rats

The effect of AMAF on insulin resistance and insulin sensitivity using three mathematical indices, HOMAIR, HOMA- $\beta$ and QUICKI scores, in experimental rats before and after treatment are given in Table 4. HOMA-IR values were increased $(6.15 \pm 1.11)$ in diabetic rats compared to those in normal rats $(2.54 \pm 0.39)$ indicating increased insulin resistance in the diabetic rats. HOMA- $\beta$ and QUICKI values were decreased in diabetic rats suggesting the lower insulin sensitivity in these animals when compared to normal rats. After 30 days of AMAF or glibenclamide treatment HOMA-IR, HOMA- $\beta$ and QUICKI values were significantly improved to near normal levels in diabetic treated groups. HOMA-IR, HOMA- $\beta$ and QUICKI scores of normal treated rats did not show any changes compared to normal control rats.

Table 3. Effects of active fraction (AMAF) of A. malabarica on fasting blood glucose and plasma insulin levels in normal and diabetic rats. BT: before treatment, AT: After treatment, NC: normal control rats, NT: normal rats treated with AMAF, DC: diabetic control rats, DT: diabetic rats treated with AMAF and DG: diabetic rats treated with glibenclamide. Values are calculated as mean \pm S.D $(n=6)$. Values not sharing a common superscript letter differ significantly at $\mathrm{p}<0.05$ (DMRT)

\begin{tabular}{|c|c|c|c|c|c|c|c|}
\hline \multirow{2}{*}{ Groups } & \multicolumn{5}{|c|}{ Blood glucose $(\mathrm{mg} / \mathrm{dL})$ at different days during the experimental period } & \multicolumn{2}{|c|}{ Plasma insulin $(\mu \mathrm{U} / \mathrm{l})$} \\
\hline & BT & $8^{\text {th }}$ day & $15^{\text {th }}$ day & $22^{\text {nd }}$ day & 31 st day & BT & AT \\
\hline $\mathrm{NC}$ & $84.4 \pm 3.2^{\mathrm{a}}$ & $81.6 \pm 3.6^{a}$ & $83.4 \pm 2.9^{a}$ & $83.2 \pm 4.4^{\mathrm{a}}$ & $82.6 \pm 3.9^{a}$ & $12.7 \pm 1.6^{\mathrm{a}}$ & $12.5 \pm 0.8^{a}$ \\
\hline NT & $84.6 \pm 6.7 \mathrm{a}$ & $87.6 \pm 5.6^{\mathrm{a}}$ & $82.83 \pm 4.3^{\mathrm{a}}$ & $85.8 \pm 2.9^{\mathrm{a}}$ & $85.6 \pm 3.1^{\mathrm{a}}$ & $11.8 \pm 1.7^{a}$ & $12.1 \pm 1.2^{\mathrm{a}}$ \\
\hline DC & $368.5 \pm 63.0^{b}$ & $371.3 \pm 69.6^{\mathrm{d}}$ & $386.1 \pm 77.1^{\mathrm{c}}$ & $368.5 \pm 78.3^{c}$ & $349.6 \pm 80.7^{c}$ & $6.6 \pm 0.9^{c}$ & $6.1 \pm 0.6^{c}$ \\
\hline DT & $369.3 \pm 35.5^{b}$ & $281.8 \pm 12.3^{b}$ & $219.8 \pm 14.3^{b}$ & $130.1 \pm 44.4^{\mathrm{a}}$ & $117.8 \pm 21.9^{a}$ & $6.5 \pm 0.8^{c}$ & $9.6 \pm 0.6^{b}$ \\
\hline DG & $361.5 \pm 25.6^{b}$ & $285.4 \pm 11.6^{b}$ & $273.3 \pm 12.9^{b}$ & $169.1 \pm 21.5^{b}$ & $159.8 \pm 25.4 b$ & $6.9 \pm 0.5^{c}$ & $8.4 \pm 1.1^{b}$ \\
\hline
\end{tabular}


Table 4. Effect of active fraction (AMAF) of A. malabarica on insulin sensitivity in normal and experimental diabetic rats. NC: normal control rats, NT: normal rats treated with AMAF, DC: diabetic control rats, DT: diabetic rats treated with AMAF and DG: diabetic rats treated with glibenclamide. Values are calculated as mean \pm S.D from six rats in each group. Values not sharing a common superscript letter differ significantly at $\mathrm{p}<0.05$ (DMRT)

\begin{tabular}{lcccccc}
\hline Groups & \multicolumn{2}{c}{ Before Treatment } & \multicolumn{4}{c}{ After Treatment } \\
& HOMA-IR & HOMA- $\beta \%$ & QUICKI & HOMA-IR & HOMA- $\beta \%$ & QUICKI \\
\hline NC & $2.54^{\mathrm{b}} \pm 0.39$ & $211.68^{\mathrm{b}} \pm 22.80$ & $0.332^{\mathrm{b}} \pm 0.007$ & $2.53^{\mathrm{b}} \pm 0.10$ & $245.57^{\mathrm{b}} \pm 56.59$ & $0.332^{\mathrm{b}} \pm 0.002$ \\
NT & $2.45^{\mathrm{b}} \pm 0.36$ & $228.61^{\mathrm{b}} \pm 10.72$ & $0.334^{\mathrm{b}} \pm 0.007$ & $2.53^{\mathrm{b}} \pm 0.30$ & $217.68^{\mathrm{b}} \pm 32.83$ & $0.331^{\mathrm{b}} \pm 0.005$ \\
DC & $6.15^{\mathrm{a}} \pm 1.11$ & $8.18^{\mathrm{a}} \pm 2.11$ & $0.295^{\mathrm{a}} \pm 0.008$ & $5.61^{\mathrm{a}} \pm 0.65$ & $7.42^{\mathrm{a}} \pm 1.72$ & $0.298^{\mathrm{a}} \pm 0.004$ \\
DT & $5.95^{\mathrm{a}} \pm 0.61$ & $7.72^{\mathrm{a}} \pm 1.27$ & $0.295^{\mathrm{a}} \pm 0.003$ & $2.82^{\mathrm{b}} \pm 0.36$ & $68.38^{\mathrm{d}} \pm 20.81$ & $0.326^{\mathrm{b}} \pm 0.004$ \\
DG & $6.18^{\mathrm{a}} \pm 0.63$ & $8.40^{\mathrm{a}} \pm 0.92$ & $0.294^{\mathrm{a}} \pm 0.004$ & $3.30^{\mathrm{c}} \pm 0.51$ & $33.69^{\mathrm{c}} \pm 9.91$ & $0.320^{\mathrm{c}} \pm 0.006$ \\
\hline
\end{tabular}

Effect of AMAF on total hemoglobin and glycosylated hemoglobin levels of normal and diabetic rats

Total hemoglobin $(\mathrm{Hb})$ and glycosylated hemoglobin (HbA1c) levels of the experimental groups of rats are shown in Fig. 3. HbA1c of diabetic control rats were significantly higher than those of normal rats. However, the treatment with AMAF significantly decreased the levels of HbA1c (Fig. 3A) in diabetic rats. Glibenclamide treatment has also resulted in improvement in the HbA1c levels of diabetic rats but the improvement is significantly lower than that with AMAF. A reduction in the total hemoglobin levels were observed in diabetic untreated rats when compared to normal rats. In case of diabetic treated rats either with AMAF or glibenclamide the total hemoglobin levels were significantly increased (Fig. 3B). No significant changes in HbA1c or $\mathrm{Hb}$ levels were observed in normal treated rats.

\section{LC-SRM/MS and GC-MS analysis of $A M A F$ \\ Phenolic/flavonoid compounds} of AMAF were identified and quantified using LC-SRM/MS by comparing with different standard phenolic compounds. AMAF contained significant levels of leutolin $(28 \mathrm{ng} / \mathrm{mg})$, caffeic acid $(0.85 \mathrm{ng} / \mathrm{mg})$ and quinic acid $(0.52 \mathrm{ng} / \mathrm{mg})$. On the other hand chlorogenic acid and kaempferol were identified but found below quantitation levels in AMAF. The chromatogram of the phenolics/flavanoids is shown in Fig. 4A and their molecular weights, chemical formulae and their retention times are given in Table 5 . Twelve fatty acids were detected and identified in AMAF using GC-MS analysis (Table 6). The representative mass spectrogram of AMAF is presented in Fig. 4B. These compounds were detected and identified by their fragmentation pattern and in conjunction with the NIST library.

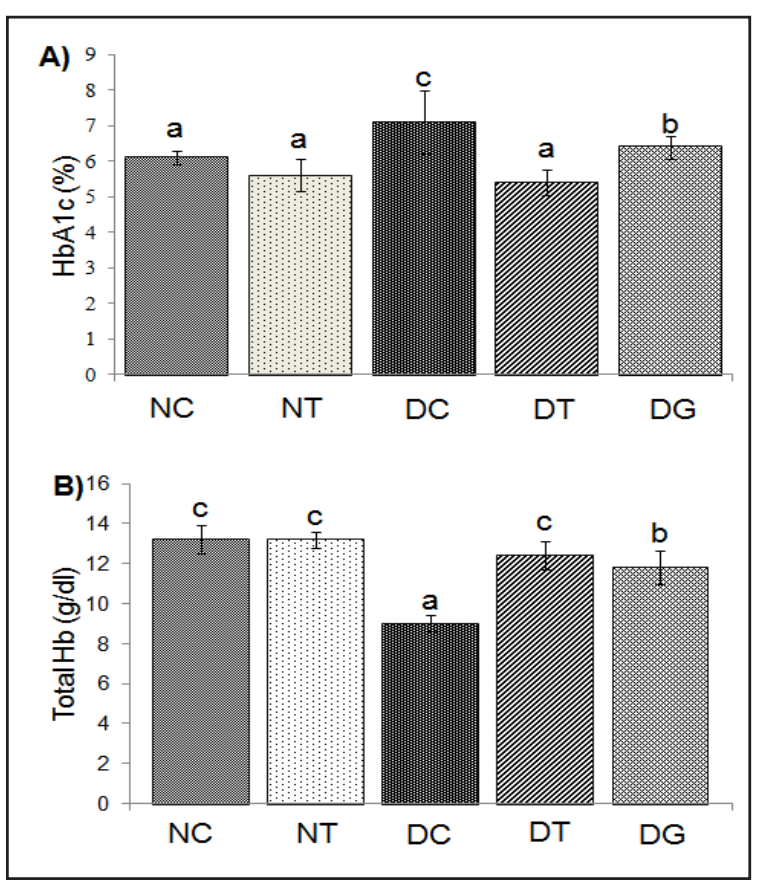

Fig. 3. Effect of active fraction of Anisomeles malabarica (AMAF) on the levels of HbA1c (A) and total hemoglobin (B) in normal and diabetic rats. $n=6, N C$ : normal control rats, NT: normal rats treated with AMAF, DC: diabetic control rats, DT: diabetic rats treated with AMAF and DG: diabetic rats treated with glibenclamide. Values are presented in mean \pm standard deviation. Values not sharing a common superscript letter differ significantly at $\mathrm{p}<0.05$ (DMRT). 


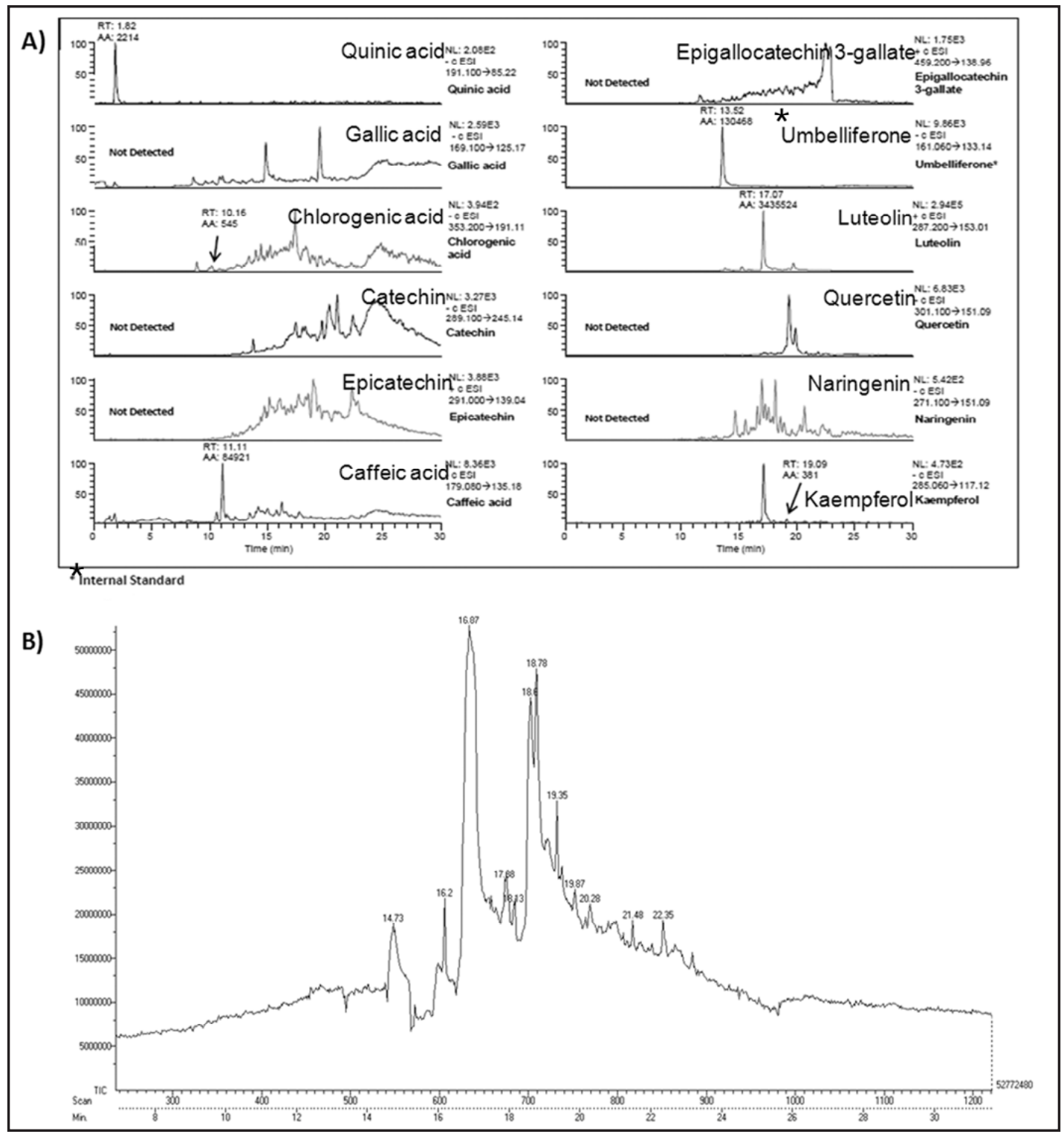

Fig. 4. A) LC-SRM/MS phenolics/flavonoid chromatograms of AMAF; B) GC-MS chromatogram of AMAF.

Table 5. Quantification of phenolics/flavonoids in AMAF by LC-SRM/MS analysis. BLQ: Below quantification level

\begin{tabular}{lllcll}
\hline S.No & Compounds & $\begin{array}{l}\text { Retention } \\
\text { Time } \\
\text { (minutes) }\end{array}$ & $\begin{array}{c}\text { Molecular Weight } \\
\text { (g/mol) }\end{array}$ & $\begin{array}{l}\text { Molecular } \\
\text { formula }\end{array}$ & $\begin{array}{l}\text { Concentration } \\
\text { (ng/mg) }\end{array}$ \\
\hline 1 & Quinic acid & 1.82 & 192.17 & $\mathrm{C}_{7} \mathrm{H}_{12} \mathrm{O}_{6}$ & 0.52 \\
2 & Chlorogenic acid & 10.16 & 354.31 & $\mathrm{C}_{16} \mathrm{H}_{18} \mathrm{O}_{9}$ & $\mathrm{BLQ}$ \\
3 & Caffeic acid & 11.11 & 180.16 & $\mathrm{C}_{9} \mathrm{H}_{8} \mathrm{O}_{4}$ & 0.85 \\
4 & Luteolin & 17.01 & 286.24 & $\mathrm{C}_{15} \mathrm{H}_{10} \mathrm{O}_{6}$ & 28.40 \\
5 & Kaempferol & 19.09 & 286.23 & $\mathrm{C}_{15} \mathrm{H}_{10} \mathrm{O}_{6}$ & $\mathrm{BLQ}$ \\
\hline
\end{tabular}


Table 6. The list of compounds present in the AMAF with their retention times, molecular weights and molecular formulas

\begin{tabular}{lllll}
\hline S.No & Compound name & $\begin{array}{l}\text { Retention } \\
\text { Time }\end{array}$ & $\begin{array}{l}\text { Molecular } \\
\text { weight }\end{array}$ & $\begin{array}{l}\text { Molecular } \\
\text { formula }\end{array}$ \\
\hline 1 & Eicosanoic acid/Arachidic Acid & 14.73 & 312.5 & $\mathrm{C}_{20} \mathrm{H}_{40} \mathrm{O}_{2}$ \\
2 & 2-Methyl-1-hexadecanol & 14.78 & 256.4 & $\mathrm{C}_{17} \mathrm{H}_{360}$ \\
3 & Methyl 13-methylpentadecanoate & 16.20 & 270.4 & $\mathrm{C}_{17} \mathrm{H}_{34} \mathrm{O}_{2}$ \\
4 & Palmitic anhydride/Hexadecanoic anhydride & 17.00 & 494.8 & $\mathrm{C}_{32} \mathrm{H}_{62} \mathrm{O}_{3}$ \\
5 & Oleic acid & 17.93 & 282.4 & $\mathrm{C}_{18} \mathrm{H}_{34} \mathrm{O}_{2}$ \\
6 & Methyl 11-(3-pentyl-2-oxiranyl) undecanoate & 18.13 & 312.4 & $\mathrm{C}_{19} \mathrm{H}_{36} \mathrm{O}_{3}$ \\
7 & 6-octadecenoic acid & 18.60 & 282.4 & $\mathrm{C}_{18} \mathrm{H}_{34} \mathrm{O}_{2}$ \\
8 & Hexadecanoic acid,2-hydroxy-1-(hydroxymethyl) ethyl & 19.35 & 286.4 & $\mathrm{C}_{17} \mathrm{H}_{34} \mathrm{O}_{3}$ \\
& ester & 19.87 & & \\
9 & 9-Hexadecenoic acid/palmitoleic acid & 20.28 & 254.4 & $\mathrm{C}_{16} \mathrm{H}_{30} \mathrm{O}_{2}$ \\
10 & 10,13-octadecadiynoic acid, methyl ester & 294.4 & $\mathrm{C}_{19} \mathrm{H}_{34} \mathrm{O}_{2}$ \\
11 & 4-hexyl-1-(7-methoxycarbonylheptyl) [4.4.0]deca-2,5,7- & 21.48 & 372.5 & $\mathrm{C}_{25} \mathrm{H}_{40} \mathrm{O}_{2}$ \\
& triene & & & $\mathrm{C}_{28} \mathrm{H}_{25} \mathrm{NO}_{7}$ \\
12 & 3,8,8-Trimethoxy-3-piperidyl-2,2- binapthalene-1,1,4,4- & 22.35 & 487.5 & \\
\hline
\end{tabular}

\section{Discussion}

In recent years, plant-based therapies are getting more attention for the management of diabetes mellitus particularly in the developing countries $[6,18]$. Herbs from Lamiaceae family are used for food preservation, culinary flavors and treatment of common illnesses as traditional medicine due to the presence of various phytochemicals and antioxidants [19]. Phenolics are an important class of phytochemicals with significant antioxidant properties which play a potential role in managing chronic diseases including diabetes mellitus [20]. Anisomeles malabarica (AM) is an aromatic herb belonging to Lamiaceae family, which is a great source of phenolics and natural antioxidants. Our initial acute treatment studies using different solvent extracts of leaves of $A$. malabarica revealed the maximum anti-hyperglycemic effect of ethyl acetate extract compared to the other solvent (hexane, methanol and aqueous) extracts. Other studies also demonstrated the ethyl acetate soluble active principles in lowering blood glucose levels [21, 22]. An advantage of using ethyl acetate for extraction is, it excludes the glycosides and hyperglycemic components that often interfere with anti-hyperglycemic or hypoglycemic effects of herbal products [23]. Our comparative studies with a known oral hypoglycemic drug, glibenclamide, indicated that the efficacy of the ethyl acetate extract is higher than that of glibenclamide. Additionally the improved glycemic control by oral hypoglycemic agents indicates the presence of remnant pancreatic $\beta$-cells in STZ induced diabetic rats or mice [24]. Further bioactivity guided fractionation of the ethyl acetate extract led to the identification of active fraction (AMAF) with higher anti-hyperglycemic activity than that of the solvent extracts. No hypoglycemia was observed during the treatment period with either crude solvent extracts or the active fraction. Further, the efficacy of AMAF at a dosage of $50 \mathrm{mg} / \mathrm{kg}$ b.w in reducing the blood glucose levels is much higher than that of the glibenclamide. In general active principle/s enriched fractions, like AMAF in the current study, demonstrate increased anti-hyperglycemic activity at lower doses when compared to plant crude extracts. This may not only be due to anticipated enrichment of the active principle(s) but also because of elimination of potential hyperglycemic compounds.

Oral glucose tolerance study indicated that the active fraction significantly improved the glucose tolerance in diabetic treated rats and it is higher in magnitude compared to that of glibenclamide. Elevated blood glucose stimulates insulin secretion from $\beta$-cells of pancreas thereby increasing peripheral glucose consumption and controls the glucose homeostasis through different mechanisms [25]. This is deranged in diabetic condition leading to glucose 


\section{Cellular Physiology Cell Physiol Biochem 2017;43:1689-1702 \begin{tabular}{ll|l} 
and Biochemistry & $\begin{array}{l}\text { DOI: 10.1159/000484030 } \\
\text { Published online: October 18, } 2017\end{array}$ & $\begin{array}{l}\text { O } 2017 \text { The Author(s). Published by S. Karger AG, Basel } \\
\text { www.karger.com/cpb }\end{array}$ \\
\cline { 2 - 3 }
\end{tabular} \\ Kotha et al.: Anti-Diabetic Activity of Anisomeles malabarica}

intolerance. In our studies AMAF treated diabetic rats' blood glucose levels were brought down to near normal within 3 hours compared to the diabetic control group, indicating the beneficial role of AMAF in glucose utilization. It is well established that the effect of glibenclamide on glucose tolerance has been attributed to the enhanced activity of beta cells of the pancreas resulting in increased secretion of insulin. So the mechanism behind this beneficial effect of AMAF on glucose tolerance potentially may be due to stimulating remnant pancreatic $\beta$-cells, regeneration of $\beta$-cells or an insulin-like activity.

Decreased levels of total hemoglobin in diabetic rats, in the current study, is not very surprising as anemia was reported commonly in diabetics [26]. Diabetic untreated rats showed significantly increased levels of HbA1c indicating poor glycemic control. In chronic hyperglycemia increased glycosylation of number of proteins including hemoglobin were reported [27]. Administration of AMAF to diabetic rats for 30 days normalized the total hemoglobin and HbA1c levels. It could be due to improved glycemic control after the treatment with the active fraction of $A$. malabarica.

Further to understand the mechanism of action of the AMAF, we measured the insulin levels. The decreased plasma insulin levels of diabetic rats were significantly elevated after the treatment with the active fraction indicating potential $\beta$-cell regenerative and/ or stimulatory (secretogogue) activity of the AMAF. Previously numerous phytochemical constituents were reported to improve glycemic control by stimulating remnant $\beta$-cells, increasing the mass of $\beta$-cells and/or enhancing the insulin action [28, 29]. Additionally fasting or postprandial hyperglycemia is a common pathogenesis of diabetes mellitus which is induced by partial pancreatic $\beta$-cell destruction and/or insulin resistance [30]. The quantitative assessment of insulin resistance (HOMA-IR) and insulin production/ $\beta$-cell function (HOMA- $\beta$ ) are key factors to assess control of diabetes and glucose homeostasis [31]. HOMA-IR is an important measure to evaluate insulin resistance that indicates microvascular and macro-vascular complication risk [32]. In our studies, insulin sensitivity (QUIKI) and $\beta$-cell function (HOMA- $\beta$ ) indices were improved significantly in diabetic rats treated with AMAF when compared to diabetic control rats. Improvement of $\beta$-cell function by the AMAF could be due to regeneration of $\beta$-cells or enhanced $\beta$-cell function compared to diabetic untreated control rats. HOMA-IR indices of diabetic control rats were significantly elevated when compared to normal control rats. After the oral administration of AMAF to diabetic rats HOMA-IR was brought down to near normal indicating that the AMAF could decrease the insulin resistance through improved tissue sensitivity to insulin or insulin secretogogue activity or both.

In the present study, we used LC-SRM/MS to verify the presence of phenolic compounds in AMAF. Our studies revealed the presence of phenolic compounds such as quinic acid, caffeic acid, leutolin, chlorogenic acid and kaemphferol. Some of the beneficial roles of AMAF in STZ induced diabetic animals can be attributed to the phenolic compounds reported here. These compounds were shown to significantly regulate various insulin and diabetes associated pathologies in diabetics. Quinic acid is the polyphenol-rich compound, which has been reported to have significant anti-hyperglycaemic activity with the combination of quercetin [33]. Jung et al., demonstrated the potential anti-hyperglycemic and antioxidant activity of caffeic acid in $\mathrm{db} / \mathrm{db}$ mice [34]. The natural flavonoids, luteolin, that we identified in AMAF is present in many vegetables and fruits. Luteolin ameliorates insulin resistance and inhibits alpha-amylase and alpha-glucosidase enzyme activities [35, 36]. Similarly, kaempferol is another typical dietary flavonoid that was shown to have many beneficial activities including anti-diabetic, antioxidant, and anti-inflammatory through promoting functions of pancreatic $\beta$-cell [37]. It was also shown to have positive effect on lipid metabolism, stimulate insulindependent glucose uptake and improve insulin resistance [38]. Chlorogenic acid, one of the most abundant polyphenol compounds in the human diet was also identified by us in AMAF. Previously chlorogenic acid was shown to regulate glucose and lipid metabolisms [39], restore carbohydrate metabolizing enzymes [40] and it was reported to possess antidiabetic activity [41]. These phenolic compounds, partly or in whole, are responsible for the anti-diabetic activity of $A$. malabarica that we demonstrated in this study. 
GC-MS studies have shown the presence of fatty acids, hydrocarbons and unsaturated fatty acids in the AMAF. Unsaturated fatty acids in the active fractions of Joso leaf extracts were shown to contribute for the anti-diabetic activity by rising sensitivity of PPAR-receptors and increasing the release of insulin from $\beta$-cells of pancreas [42]. Previous reports have been supporting the beneficial effects of omega-3- fatty acids, unsaturated fatty acids and polyunsaturated fatty acids on progression of diabetes, blood glucose concentration, insulin levels and antioxidant parameters in tissues of diabetic humans and animals [43-46]. Recently, Yang et al. [47] showed the beneficial effect of palmitoleic acid in the reduction of body weight increase, hyperglycemia, hypertriglyceridemia, insulin resistance and hepatic lipid accumulation. In this study, we report for the first time the presence of palmitic anhydride (hexadecanoic anhydride), 9-hexadecenoic acid (palmitoleic acid), hexadecanoic acid 2-hydroxy-1-(hydroxymethyl) ethyl ester and methyl 13-methylpentadecanoate in the active fraction of $A$. malabarica. Oleic acid is also present in the active fraction of A.malabarica. Oleic acid rich diet improves insulin production, increase insulin-stimulated glucose transport and reduce insulin resistance $[48,49]$.

The results of our studies indicate that the leaves of $A$. malabarica contain more than one active principle such as the flavonoids (luteolin and kaempferol), phenolic compounds (quinic acid, chlorogenic acid and caffeic acid) and unsaturated fatty acids with antihyperglycemic activity. Further studies are underway to characterize the active principles of anti-diabetic activity and understand the molecular mechanisms how these active principles elicit beneficial effect in the treatment of diabetes mellitus.

\section{Conclusion}

In conclusion, from the results of the present study it is clear that hexane: ethyl acetate (1:1) fraction (AMAF) of ethyl acetate extract of the leaves of Anisomeles malabarica play potential role in the management of diabetes mellitus.

\section{Abbreviations}

STZ (streptozotocin); AMAF (active fraction of Anisomeles malabarica); LC-SRM/ MS (Liquid Chromatography-Selected Reaction Monitoring/Mass Spectrometry); GCMS (Gas Chromatography-Mass Spectrometry); FBG (fasting blood glucose; OGT (oral glucose tolerance); HbA1c (glycosylated hemoglobin A1c; Hb, total hemoglobin); HOMAIR (homeostasis model assessment for insulin resistance); HOMA- $\beta$ (homeostasis model assessment for $\beta$-cell function); QUICKI (quantitative insulin sensitivity check index).

\section{Acknowledgements}

Peddanna Kotha received Junior Research Fellowship from Department of Science and Technology-Promotion of University Scientific Excellence (DST-PURSE), Sri Venkateswara University, Tirupati; Authors acknowledge the support of Indian Institute of Technology (IIT-Madras), Chennai for GC-MS studies; Padma Ramakrishnan, C-CAMP/NCBS MS-Facility, Bangalore and Dr. EGTV Kumar, SVIMS, Tirupati for insulin studies.

\section{Disclosure Statement}

The authors declare that there is no conflict of interest.

\section{References}

1 Akkati S, Sam KG, Tungha G: Eemergence of Promising Therapies in Diabetes Mellitus. J Clin Pharmacol 2011;51:796-804. 


\section{Cellular Physiology Cell Physiol Biochem 2017;43:1689-1702

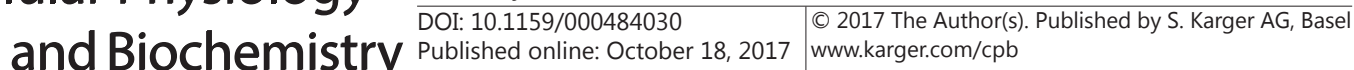

2 Mohan V, Seedat YK, Pradeepa R: The rising burden of diabetes and hypertension in southeast asian and african regions: need for effective strategies for prevention and control in primary health care settings. Int J Hypertens 2013; http://dx.doi.org/10.1155/2013/409083.

3 International Diabetes Federation: IDF diabetes atlas. 2015.

4 Ramachandran A, Snehalatha C, Ma RCW: Diabetes in South-East Asia: an update. Diabetes Res Clin Pract 2014;103:231-237.

5 Basu S, Millett C, Vijan S, Hayward RA, Kinra S, Ahuja R, Yudkin JS: The health system and population health implications of large-scale diabetes screening in India: a microsimulation model of alternative approaches. PLoS Med 2015;12:e1001827.

6 Badri KR, Rajasekhar MD, Aramgam S, Apparao C: Treatment of diabetes mellitus: Plant drugs vs oral hypoglycemic agents and insulin. Recent Prog Med Plants 2006;14:279-296.

7 Khan V, Najmi AK, Akhtar M, Aqil M, Mujeeb M, Pillai KK: A pharmacological appraisal of medicinal plants with antidiabetic potential. J Pharm Bioallied Sci 2012;4:27.

8 Gupta AK, Tandon N: Reviews on Indian medicinal plants. Indian council of medical research 2004;1:312.

9 Kotha P, Badri KR, Chippada A: Protective effect of $A$. malabarica leaves against hyperlipidemia and oxidative stress in streptozotocin induced diabetic rats; In : International Conference on Herbal and Natural Components as the Future of Pharmacology. Coimbatore, India, 2017; 256-260.

10 Vijayalakshmi R, Ranganathan R: Chemopreventive effect of Anisomeles malabarica whole plant extracts during DMBA induced hamster Buccal pouch carcinogenesis. Asian J Pharm Clin Res 2012;5:185-188.

11 Basappa G, Kumar V, Sarojini BK, Poornima DV, Gajula H: Antidiabetic activity of Anisomels indica Kuntze leaf flavonoid fraction in normal and alloxan induced diabetic mice. Plant material 2015;3:921-927.

-12 Marella S, Maddirela DR, Badri KR, Jyothi Kumar MV, Chippada A: Antihyperlipidemic and biochemical activities of mcy protein in streptozotocin induced diabetic rats. Cell Physiol Biochem 2015;35:1326-1334.

-13 Rajasekhar MD, Badri KR, Vinay Kumar K, Kassetti RB, Fatima SS, Sampath Kumar MT, Rao CA: Isolation and characterization of a novel antihyperglycemic protein from the fruits of Momordica cymbalaria. J Ethnopharmacol 2010;128:58-62.

-14 Eross J, Kreutzmann D, Jimenez M, Keen R, Rogers S, Cowell C, Vines R, Silink M: Colorimetric measurement of glycosylated protein in whole blood, red blood cells, plasma and dried blood. Ann Clin Biochem 1984;21:477-483.

15 Herbert V, Lau K-S, Gottlieb CW, Bleicher SJ: Coated charcoal immunoassay of insulin. J Clin Endocrinol Metab 1965;25:1375-1384.

16 Wallace TM, Levy JC, Matthews DR: Use and abuse of HOMA modeling. Diabetes Care 2004;27:1487-1495.

17 Katz A, Nambi SS, Mather K, Baron AD, Follmann DA, Sullivan G, Quon MJ: Quantitative insulin sensitivity check index: a simple, accurate method for assessing insulin sensitivity in humans. J Clin Endocrinol Metab 2000;85:2402-2410.

18 Pandey A, Tripathi P, Pandey R, Srivatava R, Goswami S: Alternative therapies useful in the management of diabetes: A systematic review. J Pharm Bioallied Sci 2011;3:504.

19 Carović-StanKo K, Petek M, Martina G, Pintar J, Bedeković D, Ćustić MH, Satovic Z: Medicinal plants of the family Lamiaceae as functional foods - a review. Czech J Food Sci 2016;34:377-390.

-20 Adefegha SA, Oboh G: Phytochemistry and mode of action of some tropical spices in the management of type-2 diabetes and hypertension. African J Pharm Pharmacol 2013;7:332-346.

-21 Arokiyaraj S, Balamurugan R, Augustian P: Antihyperglycemic effect of Hypericum perforatum ethyl acetate extract on streptozotocin-induced diabetic rats. Asian Pac J Trop Biomed 2011;1:386-390.

22 Irudayaraj SS, Sunil C, Duraipandiyan V, Ignacimuthu S: Antidiabetic and antioxidant activities of Toddalia asiatica (L.) Lam. Leaves in Streptozotocin induced diabetic rats. J Ethnopharmacol 2012;143:515-523.

23 Shokeen P, Anand P, Murali YK, Tandon V: Antidiabetic activity of 50\% ethanolic extract of Ricinus communis and its purified fractions. Food Chem Toxicol 2008;46:3458-3466.

24 Xu X, Liang T, Lin X, Wen Q, Liang X, Li W, Qin F, Zheng N, Ming J, Huang R: Effect of the total extract of Averrhoacarambola (Oxalidaceae) root on the expression levels of TLR4 and NF-kB in streptozotocininduced diabetic mice. Cell Physiol Biochem 2015;36:2307-2316.

25 Jarald EE, Joshi SB, Jain DC, Edwin S: Biochemical evaluation of the hypoglycemic effects of extract and fraction of Cassia fistula Linn. in alloxan-induced diabetic rats. Indian J Pharm Sci 2013;75:427.

26 Kwon E, Ahn C: Low hemoglobin concentration is associated with several diabetic profiles. Korean J Intern Med 2012;27:273-274. 


\section{Cellular Physiology Cell Physiol Biochem 2017;43:1689-1702 \begin{tabular}{ll|l} 
DOI: 10.1159/000484030 & O 2017 The Author(s). Published by S. Karger AG, Basel \\
www.karger.com/cpb
\end{tabular} \\ Kotha et al.: Anti-Diabetic Activity of Anisomeles malabarica}

27 Kesavulu MM, Rao BK, Giri R, Vijaya J, Subramanyam G, Apparao C: Lipid peroxidation and antioxidant enzyme status in Type 2 diabetics with coronary heart disease. Diabetes Res Clin Pract 2001;53:33-39.

28 Patel DK, Prasad SK, Kumar R, Hemalatha S: An overview on antidiabetic medicinal plants having insulin mimetic property. Asian Pac J Trop Biomed 2012;2:320-330.

-29 Coman C, Rugină OD, Socaciu C: Plants and natural compounds with antidiabetic action. Not Bot Horti Agrobot Cluj-Napoca 2012;40:314-325.

-30 Wilson RD, Islam MS: Fructose-fed streptozotocin-injected rat: an alternative model for type 2 diabetes. Pharmacol Reports 2012;64:129-139.

-31 Kahn SE: The relative contributions of insulin resistance and beta-cell dysfunction to the pathophysiology of type 2 diabetes. Diabetologia 2003;46:3-19.

32 Andersen LB, Boreham CAG, Young IS, Smith GD, Gallagher AM, Murray L, McCarron P: Insulin sensitivity and clustering of coronary heart disease risk factors in young adults. The Northern Ireland Young Hearts Study. Prev Med (Baltim) 2006;42:73-77.

33 Arya A, Al-obaidi MMJ, Shahid N, Ibrahim M, Noordin B, Yeng C, Wong WF, Khaing SL, Mustafa MR: Synergistic effect of quercetin and quinic acid by alleviating structural degeneration in the liver, kidney and pancreas tissues of STZ-induced diabetic rats: A mechanistic study. Food Chem Toxicol 2014;71:183196.

34 Jung UJ, Lee M, Park YB, Jeon S, Choi M: Antihyperglycemic and antioxidant properties of caffeic acid in db / db mice. Pharmacology 2006;318:476-483.

35 Xu N, Zhang L, Dong J, Zhang X, Chen YG, Bao B, Liu J: Low-dose diet supplement of a natural flavonoid, luteolin, ameliorates diet-induced obesity and insulin resistance in mice. Mol Nutr Food Res 2014;58:12581268.

-36 Asghari B, Salehi P, Sonboli A, Ebrahimi SN: Flavonoids from Salvia chloroleuca with alpha-amylse and alpha-glucosidase inhibitory effect. Iran J Pharm Res 2015;14:609-615.

-37 Al-Numair KS, Chandramohan G, Veeramani C, Alsaif MA: Ameliorative effect of kaempferol, a flavonoid, on oxidative stress in streptozotocin-induced diabetic rats. Redox Rep 2015;20:198-209.

38 Luo C, Yang H, Tang C, Yao G, Kong L, He H, Zhou Y: Kaempferol alleviates insulin resistance via hepatic IKK/ NF-kB signal in type 2 diabetic rats. Int Immunopharmacol 2015;28:744-750.

39 Meng S, Cao J, Feng Q Peng J, Hu Y: Roles of chlorogenic acid on regulating glucose and lipids metabolism: A review. Evidence-based Complement Altern Med 2013; DOI: 10.1155/2013/801457.

40 Uma C, Suganya N, Vanitha P, Bhakkiyalakshmi E, Suriyanarayanan S, John KMM, Sivasubramanian S, Gunasekaran P, Ramkumar KM: Antihyperglycemic effect of Codariocalyx motorius modulated carbohydrate metabolic enzyme activities in streptozotocin-induced diabetic rats. J Funct Foods 2014;11:517-527.

41 Vinayagam R, Jayachandran M, Xu B: Antidiabetic Effects of Simple Phenolic Acids: A Comprehensive Review. Phyther Res 2016;30:184-199.

$>42$ Orhan N, Aslan M, Demirci B, Ergun F: A bioactivity guided study on the antidiabetic activity of Juniperus oxycedrus subsp. oxycedrus L. leaves. J Ethnopharmacol 2012;140:409-415.

43 Garg A: High-monounsaturated-fat diets for patients with diabetes mellitus: a meta-analysis. Am J Clin Nutr 1998;67:577S-582S.

44 Mohan IK, Das UN: Prevention of chemically induced diabetes mellitus in experimental animals by polyunsaturated fatty acids. Nutrition 2001;17:126-151.

45 Sirtori CR, Galli C: N-3 fatty acids and diabetes. Biomed Pharmacother 2002;56:397-406.

46 Suresh Y, Das UN: Long-chain polyunsaturated fatty acids and chemically induced diabetes mellitus: effect of $\omega-3$ fatty acids. Nutrition 2003;19:213-228.

47 Yang Z-H, Miyahara H, Hatanaka A: Chronic administration of palmitoleic acid reduces insulin resistance and hepatic lipid accumulation in KK-A y Mice with genetic type 2 diabetes. Lipids Health Dis 2011;10:120.

48 Ryan M, McInerney D, Owens D, Collins P, Johnson A, Tomkin GH: Diabetes and the Mediterranean diet: a beneficial effect of oleic acid on insulin sensitivity, adipocyte glucose transport and endothelium-dependent vasoreactivity. QJM 2000;93:85-91.

49 Vassiliou EK, Gonzalez A, Garcia C, Tadros JH, Chakraborty G, Toney JH: Oleic acid and peanut oil high in oleic acid reverse the inhibitory effect of insulin production of the inflammatory cytokine TNF- $\alpha$ both in vitro and in vivo systems. Lipids Health Dis 2009;8:25. 